\title{
Ecological perspectives and children's use of the Internet: exploring micro to macro level analysis
}

\author{
Brian O’Neilla1 \\ ${ }^{a}$ Dublin Institute of Technology
}

\begin{abstract}
Age-old debates on children's encounters with media technologies reveal a long, fractured and contentious tradition within communication and media studies. Despite the fact there have been studies of effects of media use by children since the earliest days of broadcasting, the subject remains under-theorised, poorly represented in the literature and not widely understood in media policy debates. Old debates have intensified in relation to the study of children and the internet. Pitted between alarmist accounts of risks, excessive use and harmful effects on the one hand and the many accounts about "digital natives" and the transformational power of technology is the empirical project - represented by EU Kids Online among others - of building an evidence base for understanding the evolving environment for youth online engagement. In this paper, I situate that body of work in an ecological context, both in the sense of the Bronfenbrenner's bio-ecological model that has been so important in the new sociology of childhood, as well as in the more loosely defined theoretical approach of media ecology. The latter tradition, associated primarily with McLuhan and later Postman, frames the media environment as a complex interplay between technology and society in which modes of communication and mediated interaction fundamentally shape human behaviour and social life. These strands offer the basis for framing some of the issues of evidence-based policymaking relating to internet governance, regulation and youth protection online.
\end{abstract}

Keywords: children and Internet, media ecology, online risks, Bronfenbrenner, EU Kids Online

1 Dublin Institute of Technology, Grangegorman, Dublin 7, Ireland; brian.oneill@dit.ie 


\section{Introduction}

There are few issues within communication studies that cause as much heated debate as the supposed impact of media use on children's and young people's welfare. Childhood is seldom viewed neutrally (Livingstone, Haddon, \& Görzig, 2012) and the impact that media may have on children less so. Despite the longstanding nature of the debate and the extensive literature on media effects studies related to children, it is a subject that has remained relatively under-theorised and not well represented in either the mainstream of media and communications studies or in developmental psychology. The debate is a long and contentious one, reflected in a legacy of concern (Heins, 2008) that dates back to the late 1920s and through successive phases of media development that have variously included studies on the impact of cinema on children's physical and cognitive development (Jowett, Jarvie, \& Fuller, 1996), research into the psychology of radio listening for young people (Cantril \& Allport, 1935), culminating in the heated debates that raged during the 1960s about the feared harmful effects of exposure through television to violence, adult content and commercial content (Glucksmann \& Bennett, 1971). Each phase has displayed aspects of a moral panic, often fed by the hostility of incumbents. Each has in turn drawn on academic research particularly in the form of numerous effects studies. Most of such debates have also resulted in a variety of regulatory measures that seek both to curb the influence of media and to limit children's exposure. Important examples include the Payne Fund Studies which contributed to the Hays Code in 1930s Hollywood, the Surgeon General's report on curbing unregulated television networks in the United States in the 1960s (Surgeon General's Scientific Advisory Committee, 1972), the introduction of the V-chip for television during the Clinton administration as well as the ill-fated Communications Decency Act of 1996 and other equivalent measures to introduce filtering and classification of media content (Resnick \& Miller, 1996). Unifying each of these discrete traditions has been a widespread public distrust and concern about the media and their presumed negative impact on childhood.

On the face of it, children's use of information and communication technologies (ICTs), assorted digital technologies and the Internet might appear to fall into this familiar pattern except for the fact that it is counterbalanced by an alternative discourse that celebrates digital opportunities for youth and promotes utopian claims for "digital natives” (Prensky, 2001). Less apparent than with other forms of media evolution - television has almost always been viewed negatively or at best as a neutral force, neither good 
nor bad, in children's lives (Schramm, Lyle, \& Parker, 1961) - the Internet has been identified as a transformative technology for young people, bringing about a new form of literacy and mode of communication essential to their future roles as productive and participative adults and citizens. At the same time, unprecedented claims are made for its potential negative impact, such as risks of impaired cognitive development or sexual predation and exploitation that are rarely featured in "harmful media discourse” associated with traditional media (Gillespie, 2008). Accordingly, children's appropriation of digital technologies, it may be said, is subject to competing discourses and exaggerated claims on both sides: as pioneers and adopters of new disruptive technologies that digital immigrants may fail to understand or appreciate (Palfrey \& Gasser, 2010) or as helpless victims of de-humanising technologies that are ultimately destructive of childhood (American Academy of Pediatrics, 2013; Spitzer, 2012).

An important source of critical reflection on media technologies from an environmental perspective is the so-called media ecology tradition (Strate, 2004). Media ecology is a tradition within media and communications studies that has prioritized the study of how media systems, media devices and media content shape and affect human perception, understanding, feeling, and value. Media ecology characterises the pervasive role that the media plays in contemporary life as a constitutive environment in which identities are played out and in which diverse forms of communication and behaviour are practiced. For media ecologists, a crucial question is how interactions with the media environment facilitate or impede human development. This is especially the case when it comes to children and the media. Reflecting an age-old, contentious debate about children's interactions with the media, these concerns have only intensified in relation to the study of children's experiences with the Internet and online technologies. In general, media ecology perspectives have tended to combine a suspicion of the role that technology plays in children's lives with a particular interest in the potential of education to counterbalance its negative impact. Debates about the future of learning and the role played by interactive media technologies have particular relevance, therefore, for media ecologists and for an ecological approach in general.

In the following, I examine the potential of media ecology to act as a theoretical framework to support a more empirically-based approach to understanding children's media experiences. Drawing on the EU Kids Online study, I examine ecological approaches, and specifically the bioecological framework of Bronfenbrenner (1994) as a basis for theorising interaction between young Internet users and their media environment. 
Bronfenbrenner's bio-ecological framework is well-established within research on developmental aspects of childhood. However, relatively little attention has been given within this particular framework to the many technological forms of mediation in contemporary childhood. In extending its coverage to incorporate technological mediation, I draw on the work of EU Kids Online, the pan-European research network dedicated to the study of children's experiences of the Internet. Within the conceptual framework of EU Kids Online (Hasebrink, Livingstone, Haddon, \& Ólafsson, 2009), the individual child is located within specific socio-demographic contexts, shaped in turn by a range of cultural and societal factors at the national and the trans-national level. Countering both alarmist accounts of risks, excessive use and harmful effects on the one hand and the many accounts about "digital natives" and the transformational power of technology on the other, EU Kids Online has sought to build an evidence base that helps us to gain a more holistic picture of the evolving environment for youth online engagement. I argue that an „ecological” approach to studying children's online experiences helps frame the media environment as a complex interplay between technology and society in which modes of communication and mediated interaction fundamentally shape human behaviour and social life. Such an approach is a vital component in addressing some of the burning issues of evidence-based policymaking relating to Internet governance, regulation and youth protection online.

\section{Media ecology}

The most familiar ecological approaches to the media are those represented by the so-called media ecology tradition (Strate, 2004). This encompasses a body of thought associated with the North American liberal humanist tradition of Eric Havelock, Suzanne Langer, Lewis Mumford and notably Marshall McLuhan. According to Neil Postman, a media theorist also closely identified with the tradition, media ecology stems from a biological metaphor and examines the matter of how media of communication affect human perception, understanding, feeling, and value; and how our interaction with media facilitates or impedes our chances of survival (Postman, 2000). It represents the study of environments: their structure, content, and impact on people and characterises the media environment as a complex message system which imposes on human beings certain ways of thinking, feeling, and behaviour. For media ecologists, the key objective is to make explicit the layers of influence implicit within a media-dominated envi- 
ronment, examining how media structure can affect human perception, understanding, feeling and value.

Both for Postman, but also for McLuhan and other notable figures within the media ecology tradition, education has been a central theme of interest (Ross, 2009). Postman's (2000) own approach, despite the characterization of teaching as a subversive activity, regards the influence of media on education as stultifying, and decries its narcotizing effects. In an apparently conservative and reactionary stance against the technologisation of contemporary society, Postman and some fellow media ecologists argued that without reform, technologies added little to the educational curriculum and would merely reinforce the downward slide in efforts to stimulate critical thinking. Interestingly, McLuhan's own standpoint towards the educational potential of media technologies in school settings was more sympathetic, recognizing their radical potential to connect individuals and deconstruct complex systems of communication. Indeed, McLuhan's popular appeal influenced an entire generation of educators both to engage with critical media study and to introduce technologies into classrooms as tools to foster creativity, agency and critical thinking (Bates, 1984; Moody, 1999). The critical communications scholar, James Carey, was one who re-evaluated the approach to McLuhan and media ecology thinking, shifting from an initial appraisal of its influence as reactionary technological determinism to a more nuanced and appreciative evaluation of its potential to contribute to a better understanding of the different ways in which social actors adopt and use media technologies in the course of their daily lives (Carey, 1981; Grosswiler, 2006). However, the criticism of its fundamentally abstract approach and lack of attention to empirical detail remains, preventing many educationalists from following its implications or recommendations for progressive media-based education.

\section{The bio-ecological framework}

An alternative ecological approach from a social scientific perspective is the so-called bio-ecological framework developed by Bronfenbrenner and his colleagues. First introduced in the 1970s (Bronfenbrenner, 1979), and developed through subsequent decades, this is an important and widely adopted paradigm within developmental psychology, pediatrics and childhood studies. It is a model that characterises human development as a process of reciprocal interaction between a developing person and their environment, the underlying proposition of which is that in order to understand human development one must consider the actual environments in which humans 
live and grow. The ecological system is taken to be composed of a series of socially organised subsystems that support human growth and development and which encompass:

1) A microsystem based on the relationships between the developing person and their immediate environment, especially family-based relationships

2) A mesosystem involving inter relationships between two or more microsystems in which the developing person actively participates, e.g. the child's inter relationship between home and school

3) An exosystem comprising one or more settings that do not involve the developing person as an active participant, but which have a bearing on the subject

4) A macrosystem in the form of structural consistencies across the subculture or culture along with relevant belief systems or ideologies that underpin this structure

5) Finally, a chronosystem capturing the historical development of lower subsystems over time (ibid.).

These embedded or nested subsystems are frequently represented in the form of concentric circles (Figure 1) representing spheres of influence of increasing complexity in which interactions with environmental experience bring about developmental outcomes (Bronfenbrenner \& Ceci, 1994).

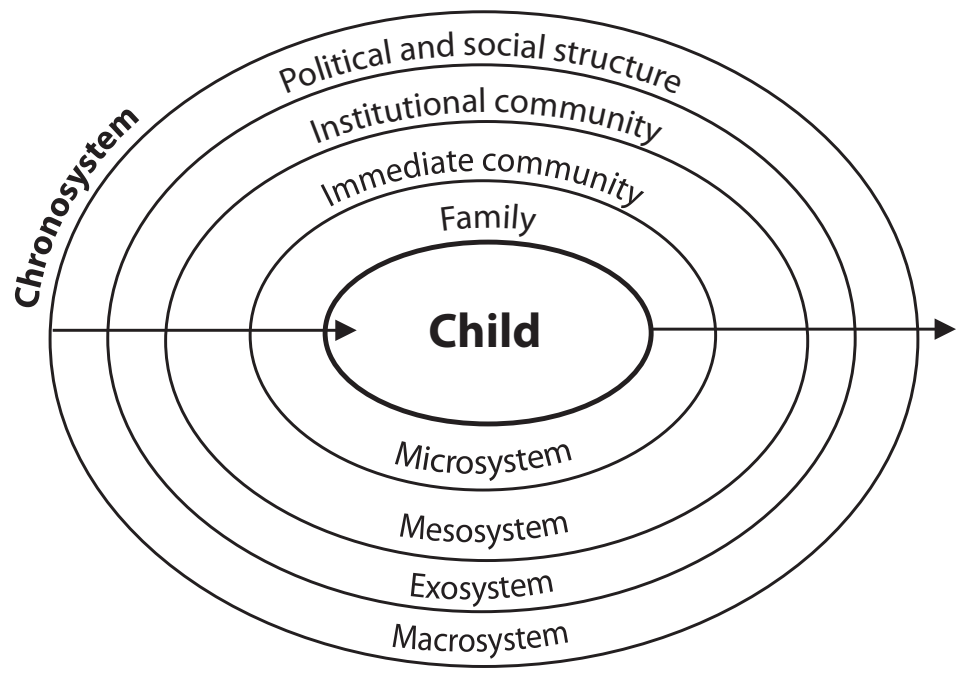

Figure 1: Bronfenbrenner's Ecological Theory of Development (Halpern \& Figueiras, 2004)

The theoretical framework underpinning this approach is summarised by Bronfenbrenner (2005) in two key propositions: 
Proposition 1: In order to develop - intellectually, emotionally, socially, and morally - a human being, whether child or adult, requires active participation in progressively more complex, reciprocal interaction with persons, objects, and symbols in the individual's immediate environment. To be effective, the interaction must occur on a fairly regular basis over extended periods of time. Such enduring forms of interaction in the immediate environment are referred to as proximal processes. Proximal processes are posited as the primary engines of development. Examples of enduring patterns of these processes are found in parent-child and child-child activities, group or solitary play, reading, learning new skills, problem solving, performing complex tasks, and acquiring new knowledge and know-how. Proximal processes are proposed as the mechanisms through which human potential for effective psychological functioning is actualized (ibid., p. 4).

Proposition 2: Proximal processes cannot structure, steer or sustain themselves. Their form, power, content, and direction vary systematically as a joint function of the characteristics of the developing person and of the environment - both immediate and more remote in which the processes are taking place; the time through the life course and the historical period during which the person has lived; and the nature of the developmental outcome under consideration (ibid., p. 4).

As Bronfenbrenner argues in The Ecology of Human Development (1979), humans appear to be unique in their capacity

... to adapt to, tolerate, and especially to create the ecologies in which it lives and grows. Seen in different contexts, human nature, which I had once thought of as a singular noun, turns out to be plural and pluralistic; for different environments produce discernible differences, not only across, but within, societies, in talent, temperament, human relations, and particularly in the ways in which each culture and subculture brings up the next generation. The process and product of making human beings human clearly varies by place and time. Viewed in historical as well as cross-cultural perspective, this diversity suggests the possibility of ecologies as yet untried that hold a potential for human natures yet unseen, perhaps possessed of a wiser blend of power and compassion than has thus far been manifested (ibid., p. xiii). 
While the bio-ecological model has been influential across diverse settings and contexts, it has as yet received relatively little attention from media scholars despite the relative flexibility of the model and the policy and educational interest in media as an environmental influence. Bronfenbrenner did not consider media like television as a proximal process as such, but rather as a 'second-order effect, in this case operating not completely within a microsystem but rather across ecological borders as an exosystem phenomenon' (1979, p. 242). His focus was primarily on human interaction and somewhat disparagingly referred to television as a near universal feature in the home that had the effect of disrupting familial interaction (Bronfenbrenner, 1975). By contrast, Jordan (2004) posits the ecological approach as important in that it maintained a simultaneous focus on the characteristics of the individual child, the critical setting of the home, and the ubiquitous cultural environment. Arguing for an expanded notion of the home as a multimedia environment, she argues that media has been intricately interwoven into home-based interactions (Jordan, 2004). Atkin et al. (1991) examining the role of cable television in the home, identified three levels of the typology as relevant to its mediation. Firstly, within the microsystem of the home, parent-child interaction directly impacts on television consumption. Secondly, the macrosystem defines modes of delivery, television's affordances and regulatory constraints. Finally, in terms of the exosystem, television is a dynamic influence, a second-order effect that, through its effect on parents and their interaction with children, operates across ecological boundaries. At each level, differentiation in parental mediation could be studied, they argue, according to macro level predictors of occupation, income, education and ethnicity and within the microsystem in terms of age, numbers and ages of children in single vs. two parent households (Atkin, Greenberg, \& Baldwin, 1991).

Atkin (2001) subsequently argued that an ecological perspective centred on the home was especially relevant in the context of a generation that has only ever experienced multimedia and availability of diverse media technologies in households. A generation of „digital natives” (Prensky, 2001) is thus presented with unprecedented choice and control in their use of and interaction with media, implying a greater role for media consumption in household interaction and that developments in the media exosystem or environment (deployment of new media services and technologies) as well as the increased importance of parental mediation in screening children's media access requires greater attention be given to the relevance of new media in proximal processes. Given the disruptive new interlinkages brought about by the Internet as a new medium, Atkin argued for 
an updating of ecological perspectives to take account of emerging online modalities. While this entails an evolution from passive television viewing in a household to more active forms of parental mediation, it constitutes a largely altered and more complex exosystem phenomenon placing greater demands and responsibilities on parents to manage the flow of media content at the level of the microsystem. This contested media context, combined with the range of social phenomena that Bronfenbrenner described as 'growing chaos' in the lives of children (childhood obesity, dysmorphic body perception, anti-social behaviour, attention deficit disorder) creates an urgent demand for researchers to investigate environmental influences on child developmental outcomes.

Johnson, responding to the growing complexity and wider availability of technology in contemporary childhood, introduced the notion of the ecological techno-subsystem, a dimension of the microsystem (Figure 2) that comprises an additional zone of interaction with both living (e.g., peers) and nonliving (e.g., hardware) elements of communication, information, and recreation technologies in immediate or indirect environments (Johnson \& Puplampu, 2008).

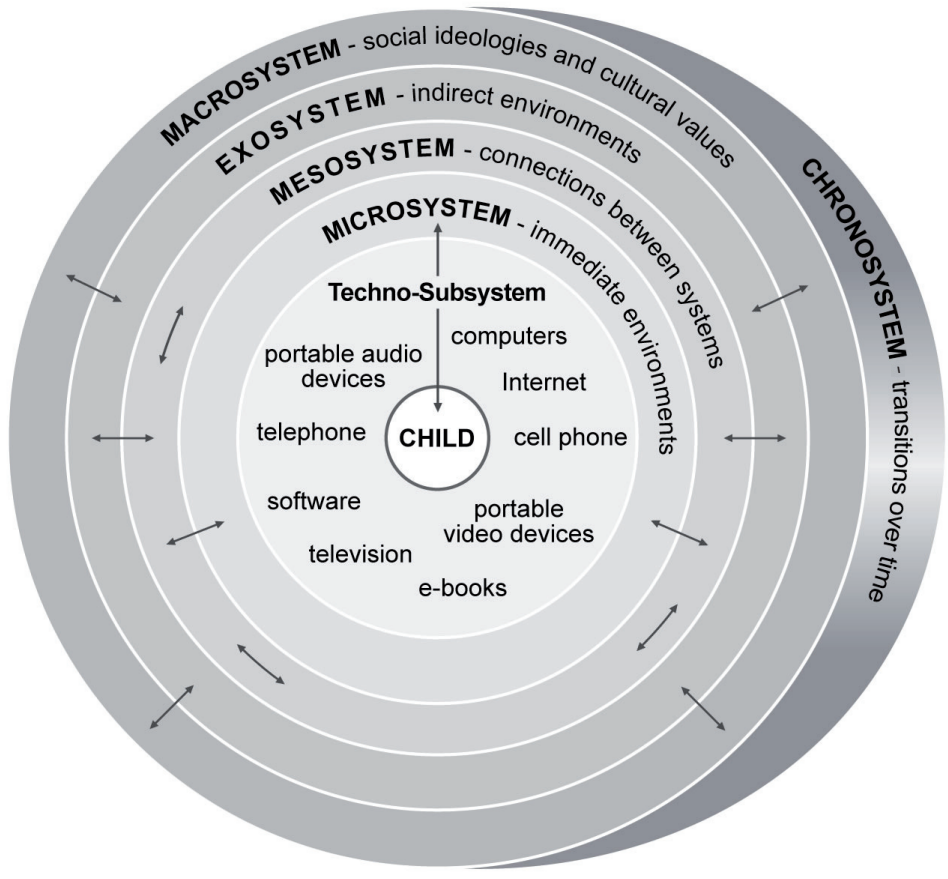

Figure 2: The Ecological Techno-Subsystem (Johnson \& Puplampu, 2008) 
By focusing on the ecological technosubsystem, Johnson and Puplampu (2008) place the emphasis on the role of technology in child development and encourage a holistic exploration of the developmental consequences of Internet use during childhood based on the mutual accommodation between the developing being and the immediate environment.

\section{The EU Kids Online theoretical framework}

EU Kids Online ${ }^{2}$ is a pan-European research network that seeks to enhance knowledge of European children's online opportunities, risk and safety. Stemming from a tradition of comparative research on the media consumption experiences of children in Europe, it uses multiple methods to map children's and parents' experience of the Internet to give realistic assessments of the risks they face as well as the responses they make.

In developing its research into children's experiences of risks and safety using Internet technologies, the EU Kids Online network has developed a working model drawing loosely on the bio-ecological approach to frame its principal research questions and to situate its findings within an appropriate interpretative framework. While theoretical analysis of children's use of new media technologies remains under-developed, Bronfenbrenner's bio-ecological framework in this context provides a useful basis for a child-centred approach to children's experiences, perspectives and actions relating to the Internet, contextualised within the structuring social influences, represented as concentric circles of family, community and culture (Livingstone et al., 2012). This working model (Figure 3) acknowledges three sets of interdependencies:

1) at the level of the individual user within the microsystem primarily of the home;

2) the level of social mediations, principally related to home, school and peer cultures; and

2 The EU Kids Online network has been funded by the EC Safer Internet Programme in three successive phases of work from 2006-14 to enhance knowledge of children's and parents' experiences and practices regarding risky and safer use of the Internet and new online technologies. As a major part of its activities, EU Kids Online conducted a face-to-face, in home survey during 2010 of 25,000 9- to 16-year-old Internet users and their parents in 25 countries, using a stratified random sample and self-completion methods for sensitive questions. Now including researchers and stakeholders from 33 countries in Europe and beyond, the network continues to analyse and update the evidence base to inform policy. For all reports, findings and technical survey information, as well as full details of national partners, please visit www.eukidsonline.net. 
3) at the national level where the country is the unit of analysis and where macrosystem phenomena of socio-economic stratification, systems of regulation and cultural values act as shaping factors.

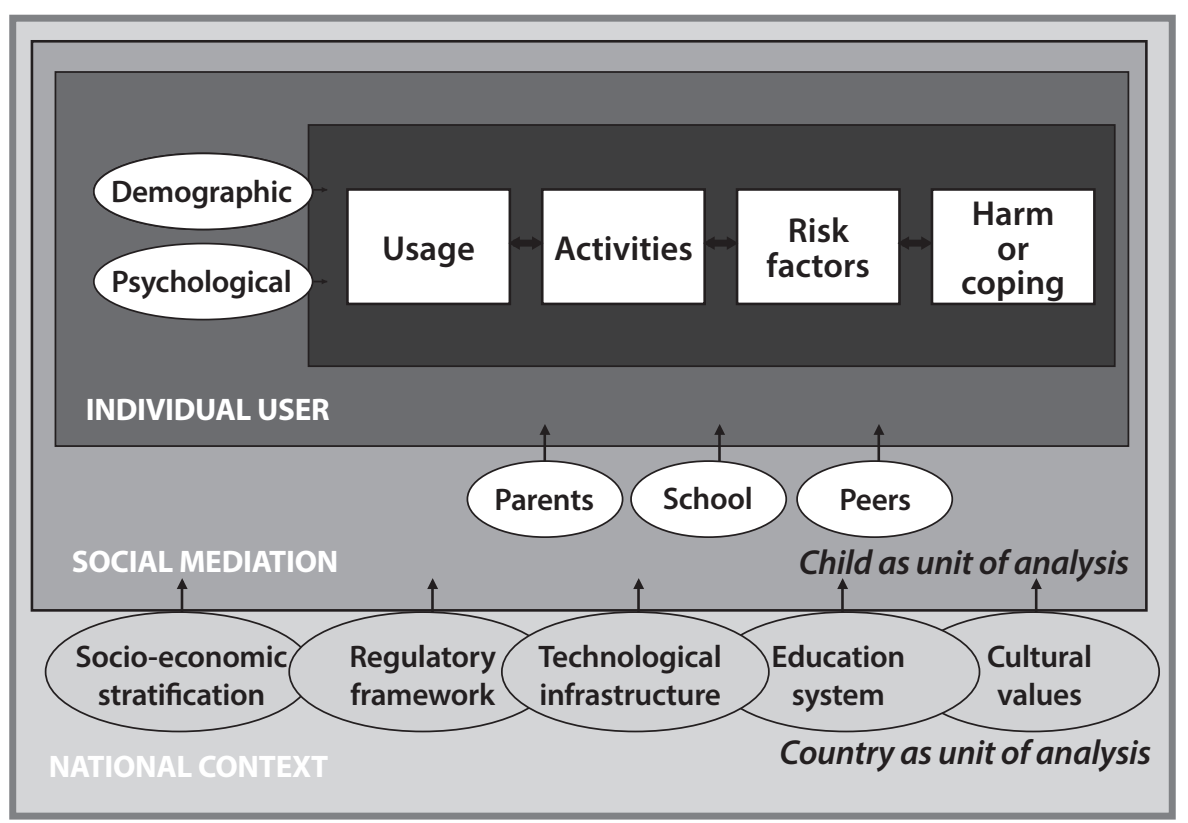

Figure 3: The EU Kids Online Model (Hasebrink, Görzig, Haddon, Kalmus, \& Livingstone, 2011)

EU Kids Online research, therefore, focuses on the everyday contexts of children's Internet use (where, how and for how long they go online) followed by accounts of their online activities in order to gauge risk factors and potential outcomes either in the form of harm as defined by children themselves or in terms of how users cope with potentially risky experiences. The risk factors were developed following a review of the available evidence base (Livingstone \& Haddon, 2009) and informed by themes of ongoing policy attention (Byron, 2008; Internet Safety Technical Task Force, 2008), but also augmented by children's own accounts of what they perceive as problematic (Smahel \& Wright, 2014). Children's experiences were differentiated primarily according to demographic factors of age, gender and socio-economic status as well as psychological factors such as emotional problems, self-efficacy and risk-taking. Social factors, in particular the mediating role played by parents, teachers and peers as well as an array of national-level factors are used to compare and differentiate findings at a more macro level. 
While there is no single, widely accepted and readily operationalized theory of children's Internet use (Livingstone et al., 2012), the application of the ecological perspective to research on children's use of the Internet helps to frame a large dataset composed of nearly 1000 variables from which theoretical constructs can be made. A number of generalised findings derive from this model to produce a general model of determinants of risk and safety that may be outlined as follows.

First, at the individual level or the level of the microsystem, as defined within the bio-ecological framework, empirical analysis provides an account of the similarities and differences between children which acknowledges that childhood is not one homogenous category and that the Internet as adopted by young people is a single entity or experience. A typology of young Internet users, developed through a cluster analysis of uses, activities and risks, identifies six user types: moderate users, risky explorers, experienced networkers, young networkers, intensive gamers and low risk novices. Table 1 outlines each type's general characteristics, classified by risk and harm, enabling general conclusions to be drawn (Hasebrink et al., 2011).

Table 1: Six user types classified by risk and harm (Livingstone et al., 2012)

\begin{tabular}{|c|c|c|}
\hline & Low risk & High risk \\
\hline Lower harm & Moderate users & Risky explorers \\
\hline Age & Younger (12.7 years) & Older (13.5 years) \\
\hline$\%$ girls & $48 \%$ & More boys (38\% girls) \\
\hline Use (minutes online/day) & Low (71) & High (118) \\
\hline Online activities (of 17) & Moderate (7.7) & Very high (13.2) \\
\hline Risky online activities (of 5) & Low (0.7) & Very high (2.1) \\
\hline Online skills (of 8) & Moderate (3.9) & Fairly high (5.8) \\
\hline \multirow[t]{2}{*}{$\begin{array}{r}\text { Restrictive parental mediation } \\
\text { (reported by child) }\end{array}$} & Moderate (87\%) & Low (69\%) \\
\hline & & $\begin{array}{l}\text { Experienced } \\
\text { networkers }\end{array}$ \\
\hline Age & & Oldest (14.1 years) \\
\hline$\%$ girls & & More girls (67\%) \\
\hline Use (minutes online/day) & & High (108) \\
\hline Online activities (of 17) & & High (9.6) \\
\hline Online skills (of 8) & & Fairly high (5.4) \\
\hline
\end{tabular}




\begin{tabular}{|c|c|c|}
\hline & Low risk & High risk \\
\hline Risky online activities (of 5) & & High (1.5) \\
\hline $\begin{array}{r}\text { Restrictive parental mediation } \\
\text { (reported by child) }\end{array}$ & & Moderate (81\%) \\
\hline Medium harm & Young networkers & Intensive gamers \\
\hline Age & Younger ( 12.7 years) & Older (13.6 years) \\
\hline$\%$ girls & $55 \%$ & More boys ( $37 \%$ girls) \\
\hline Use (minutes online/day) & Low (72) & Very high (180) \\
\hline Online activities (of 17) & Low (5.2) & High (9.8) \\
\hline Risky online activities (of 5) & Moderate (1.0) & High (1.6) \\
\hline Online skills (of 8) & Moderate (3.8) & Fairly high (5.4) \\
\hline $\begin{array}{r}\text { Restrictive parental mediation } \\
\text { (reported by child) }\end{array}$ & Moderate (87\%) & Fairly low (76\%) \\
\hline Higher harm & Low risk novices & \\
\hline Age & Youngest (11.1 years) & \\
\hline$\%$ girls & $50 \%$ & \\
\hline Use (minutes online/day) & Very low (50) & \\
\hline Online activities (of 17) & Very low (3) & \\
\hline Risky online activities (of 5) & Very low (0.3) & \\
\hline Online skills (of 8) & Very low (1.7) & \\
\hline $\begin{array}{r}\text { Restrictive parental mediation } \\
\text { (reported by child) }\end{array}$ & High (96\%) & \\
\hline
\end{tabular}

Drawing on the ecological framework, some important conclusions can be drawn from this analysis at the level of individual user. Firstly, it can be seen that age is one of the main differentiating factors confirming the importance of a developmental perspective in terms of Internet use. Gender is less important except in terms of underlining well-established differences in activities. Secondly, the working hypothesis (,the more, the more”) of the more activities and use, the more opportunities and the more risks is confirmed. Children who use the Internet regularly and intensively gain more skills, avail of more online opportunities and it would seem also encounter more risks. It is vital however to distinguish between risk and harm and a third important conclusion is that risk of harm does not necessarily result in actual harm. The risk of actual harm is in fact low and strik- 
ingly it is those with low use and low risk who experience higher levels of harm. Thus, a focus on coping and resilience for vulnerable groups is more important than a focus on risk.

\section{Analysis at the level of macrosystem}

In keeping with developmental studies more generally, it is at the microsystem level of the individual user that analysis has proved to be most successful and where the clearest relationships have been identified with positive correlations between uses, activities, skills and risks. This has provided researchers with a rich resource for examining the patterns of risk, the role of mediating factors and the vulnerabilities of particular populations defined by key demographic and psychological variables.

Social mediation is also strongly represented in EU Kids Online research facilitated by separate parent and child interviews, allowing comparisons of parent/child versions of key items in the survey. Data from children about access, use and activities in school, the role of peers in providing support as well as reliance on other external sources extends the potential to analyse processes of social mediation.

It is at the cross-national level that there is significant potential for new knowledge to be created, expanding the potential of an ecological approach to include cultural and national factors. Cross-national analysis has, however, proved to be somewhat more challenging and, despite plausible hypotheses regarding differences along cultural and national lines, the resulting data is complex by nature and less amenable to easy interpretation (Lobe, Livingstone, Ólafsson, \& Vodeb, 2011). One way in which the EU Kids Online analysis has attempted to develop a macrosystem analysis has been by way of a typology of country differences. While each country displays its own particular characteristics and patterns of use, opportunities and risk, four broad categories or ideal types based on the twin dimensions of use and risk: „lower use, lower risk”, „lower use, some risk”, „higher use, some risk" and "higher use, high risk" categories were developed to represent differences at the European level. Thus, wealthier Nordic countries, the UK and Netherlands with high levels of Internet use were also more likely to have experienced higher degrees of risk with a general trend is for a positive and significant effect of GDP per capita on the degree of risk within a country (Lobe et al., 2011). However, without reliable and comparable indicators of technological infrastructure, regulation or culture, it has proved difficult to develop comparative analyses at the macro level. It was 
also the case that differences within countries are substantially larger than those between countries, thereby making generalisations difficult.

A revised classification, updating and deepening of the understanding of cross-national differences among the 25 countries has been developed by Helsper et al. (2013). This takes into account the range and type of online opportunities, risks and harm experienced by the children in each country as well as the ways in which parents mediate or regulate their children's Internet use in each country. This analysis results in four clusters which match relationships between use, risk and mediation at the country level (Figure 4) as follows:

- Supported risky explorers

- Semi-supported risky gamers

- Protected by restrictions

- Unprotected networkers (Helsper et al., 2013)

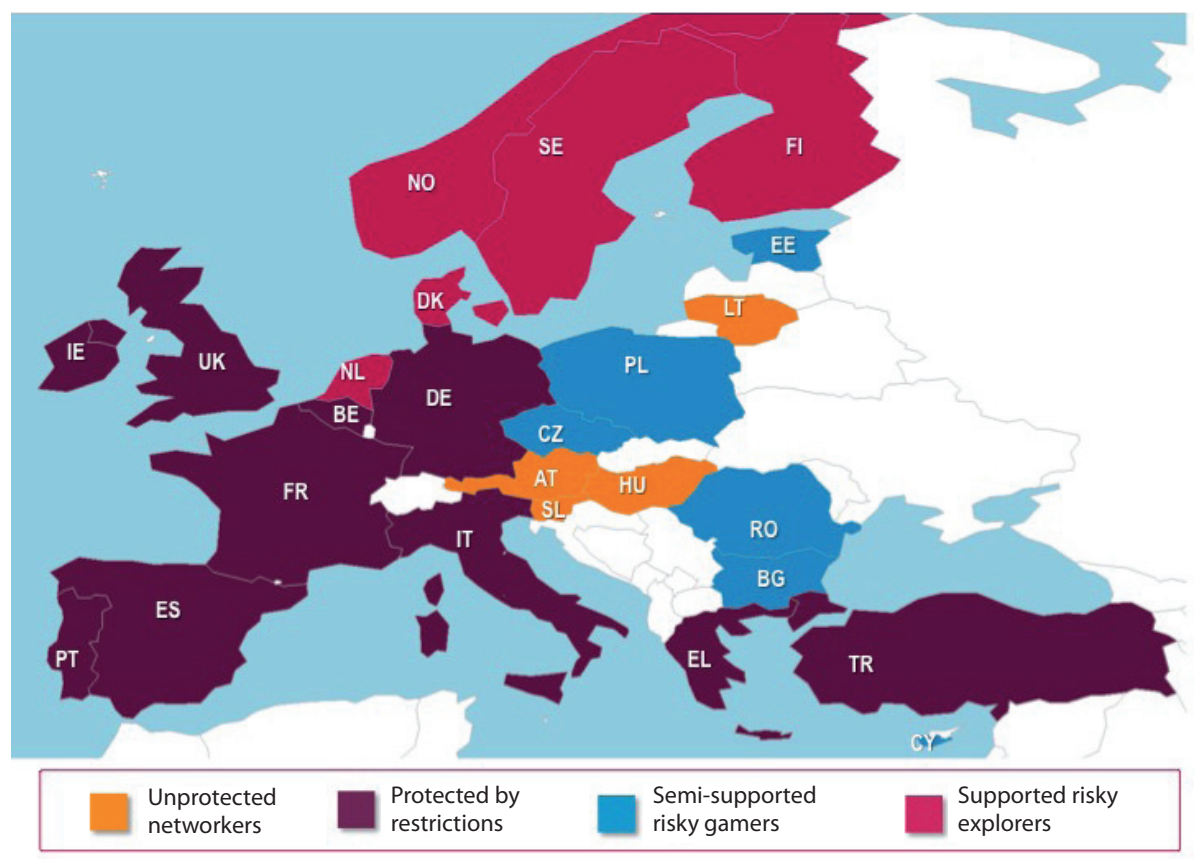

Figure 4: Classification of online opportunities, risks, harm and parental mediation clusters (Helsper et al., 2013)

A further dimension of environmental factors at the national level has been added by O'Neill (2014) in order to examine the policy context within each country and how countries within each of the clusters approach implementation of online safety for young people. The question posed in this analysis 
is: Do particular national or regional policy frameworks or policy actions reduce risk, increase online opportunities or affect the nature and extent of parental mediation? Drawing on additional research undertaken for the European Commission (Idate \& Technopolis, 2014), the analysis uses indicators for the public framework within each country (the governance arrangements, the scope of policies adopted, the legal and regulatory framework and the use of research, monitoring and evaluation to support policy) as well as actual policy implementation to further examine and highlight any apparent differences between countries.

Deriving from this analysis, the following conclusions may be advanced (O'Neill, 2014):

- Countries in the 'Protected by restrictions' cluster have done more to establish structures, and to enact legal and regulatory frameworks around online safety albeit to the detriment of promoting online opportunities.

- Countries in the 'Supported risky explorers' cluster have higher levels of public sector involvement, complementary to the Safer Internet Centres. There is more evidence of budget investment and evaluation of policy outcomes. There are higher levels of Internet diffusion and digital skills among both parents and children, and a more proactive approach to mediation.

- Countries in the 'Semi-supported risky networkers' and 'Unprotected networkers' clusters, by contrast, display a relatively uneven range of commitments. Noticeably, they invest less than other countries, have a lower level of public sector involvement, and with less evidence of coordination.

Interestingly, what the analysis of patterns of use and risk at both the microsystem level and at the level of the macrosystem shows is that for individuals just as in the political and regulatory arena, there is no single template either for accounting for user experience or for developing safer media environments. One can say there is a spectrum of activities with varying outcomes, positive as well as potentially negative, according to the different stages of development and contexts in which children and young people grow, learn and communicate. Similarly, at the national level, different methodologies exist with varying levels of impact on quality of the media environment.

It is also the case that there are different starting points when it comes to either media use or Internet safety: some users - and countries - are more supported, have better provision, possess more skills and gain more benefits. In some countries, there is quite a long history of policy involve- 
ment on the part of both the public and private sector. In other regions in Europe, developing policies and implementing strategies for Internet safety is more recent. For that reason, those parts of Europe that have had the longest experience of engaging with policy issues relating to the Internet and young people, and of balancing the competing demands of promoting young people's opportunities while protecting against the most pressing risks, provide a crucial guide for future solutions.

\section{Conclusion}

A frequently aired criticism of the ecological perspective on child development concerns its broadness and the consequent difficulty in testing or evaluating all of the components empirically. Within the ecological approach, 'everything counts' and it is difficult therefore to develop an explanatory model or to provide a clear explanatory framework or predictor as to outcomes (Downes, 2014). Against this, as argued in the foregoing, a number of benefits to the ecological perspective stand out, overweighing its limitations as an explanatory framework in favour of its potential as an interpretative framework. This includes a focus on process rather than objects and posits subjects as developing and learning-oriented beings. The ecological perspective is also a framework that encourages „connecting the dots" between microsystem phenomena and cultural context at the level of the macrosystem. It rejects an outright technological determinist point of view and supports a social shaping of technology whilst acknowledging that expectations are framed within received and structured environmental conditions. Finally, it promotes a longitudinal and historically evolving point of view that tends to get lost in large-scale cross sectional studies.

Applying the analysis and some of the key contributions that EU Kids Online makes to an ecological perspective, Livingstone (2013) has summarized a number of general themes which contribute to an ecological understanding of young people's use of Internet technologies. These may be summarized under five general headings that provide a foundation for future research and for a longer-term assessment of the implications of new media technologies in educational settings (ibid.):

1. Children are agents living in a world largely not of their own making. Children may be in the vanguard of adoption of new media technologies and adept at mastering new devices with apparent ease. However, it is a mistake to either impute that they are entirely 'media-savvy' on the one hand, or mere victims of external media forces, on the other. Research 
shows that children enact a variety of roles in relation to the media they use: they act as recipients, participants and actors in networks of social relationships shaped by their prior experiences and their family contexts. The Internet affords a variety of benefits and presents a range of risks that may be amplified according to the social contexts in which they are experienced. Educational deployment, accordingly, has to be socially contextualized and sensitive to the opportunities, skills, experiences and constraints that children will encounter.

2. Using the Internet affords children both opportunities and risks and the two go hand in hand. The media technologies used by children are in themselves neither good nor bad. They offer benefits and harms, risks and opportunities and the two, again as borne out by evidence, coincide. Therefore, educationalists must seek to ensure that in managing risk, they do create unintended consequence of reducing opportunities. Similarly, it is a mistake to promote online opportunities with no thought to the consequences for risk; nor can restrictions be implemented to reduce risk without thinking of the possible costs to children's online opportunities.

3. Risk refers to the statistical probability (not inevitability) of harm and so is not inherently bad. Risk has dominated discussion of the role played by new media technologies and the Internet in the lives of children, especially in educational contexts. Schools tend to be very risk conscious and therefore seek to be as risk-averse as possible in their deployment of technologies. However, as EU Kids Online has shown, the risks that upset children are not always the same as those that worry adults. It may be that in seeking to protect children either at home or school, either the wrong risks are identified or that other harms experienced by children fail to get attention. Research suggests that it is vital to listen to young people in relation to the risks that bother them most (e.g. cyberbullying) and to focus less on some of the more sensationalist risks that are by their nature rare (e.g. stranger danger and risk of sexual predation). It is important to recognize also that with the rise of user-generated content, young people are also actors in contributing to risk and harm and that children's own agency needs to be attended to.

4. Individual, domestic and cross-cultural factors all shape children's online experiences. The research evidence collected by EU Kids Online provides a rich resource to examine the variety of factors from individual, social and cross-cultural levels. From its findings, age emerges as the main factor differentiating children's experiences; next most influential is whether they have psychological difficulties or are risk-takers. 
Parental use of and familiarity with the Internet is also important and appears to matter more than socio-economic status (SES). Active parental mediation rather than overly restrictive approaches also helps to improve children's online experiences. The comparative nature of the analysis allows for further exploration of cross-cultural differences and a preliminary assessment of the extent to which wealthier countries and greater investment in technologies in classrooms leads to better outcomes for children. Cross-country comparisons remain, however, a challenging area of research and require further data collection and detailed analysis.

5. More and more effective multi-stakeholder interventions are needed, as described by former EC Vice President, Neelie Kroes, 'to make the Internet a better place for kids,'. EU Kids Online has argued that policy making to be effective must be truly-evidence based. To date, approaches to regulation and to educational interventions have been insufficiently informed by data on young people's actual experiences of the technologies themselves. In promoting the benefits of new media technologies for young people, it is vital therefore that all representative elements of the media environment are represented, including industry which is distinctively positioned to enhance the design of online services (e.g. SNS) and their safety features (e.g. reporting tools, parental controls) and teachers and others who work with children who can provide more effective awareness-raising and support to empower youth and improve safety. In this way, education has a unique position to reach all children in imparting essential skills and to support learning experiences that build the resilience of children and young people and foster long term digital citizenship.

In conclusion, as this paper has argued, an 'ecological' approach to studying children's online experiences helps frame the media environment as a complex interplay between technology and society in which modes of communication and mediated interaction fundamentally shape human behaviour and social life. Such an approach is a vital component in addressing some of the burning issues of evidence-based policymaking relating to Internet governance, regulation and youth protection online. 


\section{References}

American Academy of Pediatrics (2013). Children, adolescents, and the media. Pediatrics, 132(5), 958-961. Retrieved from http://pediatrics.aappublications.org/content/132/5/958.full.pdf+html. doi: http://dx.doi.org/10.1542/peds.2013-2656

Atkin, D. J. (2001). Home ecology and children's television viewing in the new media environment. In J. Bryant \& J. A. Bryant (Eds.), Television and the American family (2nd ed., pp. 49-74). London: Routledge.

Atkin, D. J., Greenberg, B. S., \& Baldwin, T. F. (1991). The home ecology of children's televison viewing: Parental mediation and the new video environment. Journal of Communication, 41(3), 40-52. doi: http://dx.doi.org/10.1111/j.1460-2466.1991.tb02322.x

Bates, T. (1984). Broadcasting in education: An evaluation. London: Constable.

Bronfenbrenner, U. (1975). Influences on human development (2nd Rev. ed.). Hinsdale, IL: Holt McDougal.

Bronfenbrenner, U. (1979). The ecology of human development. Cambridge, MA: Harvard University Press.

Bronfenbrenner, U. (2005). Growing chaos in the lives of children, youth, and families: How can we turn it around? In U. Bronfenbrenner (Ed.), Making human beings human: Bioecological perspectives on human development (pp. 185-197). Thousand Oaks, CA: Sage.

Bronfenbrenner, U., \& Ceci, S. J. (1994). Nature-nurture reconceptualized in developmental perspective: A bio-ecological model. Psychological Review, 101(4), 568-586. doi: http://dx.doi.org/10.1037/0033-295X.101.4.568

Byron, T. (2008). Safer children in a digital world: The report of the Byron Review. London: DCSF. Retrieved from www.dcsf.gov.uk/byronreview.

Cantril, H., \& Allport, G. W. (1935). The psychology of radio. New York, NY: Harper \& Brothers.

Carey, J. W. (1981). McLuhan and Mumford: The roots of modern media analysis. Journal of Communication, 31(3), 162-178. doi: http://dx.doi.org/10.1111/j.1460-2466.1981.tb00440.x

Downes, P. (2014). Conceptual framework and agenda: Beyond Bronfenbrenner $(1979,1995)$ to interrogation of blocked systems via structural indicators. In Access to education in Europe (pp. 29-48). Dordrecht: Springer Netherlands. doi: http://dx.doi.org/10.1007/978-94-017-8795-6_3

Gillespie, A. (2008). Child exploitation and communication technologies. Lyme Regis, Dorset: Russell House Publishing.

Glucksmann, A., \& Bennett, S. (1971). Violence on the screen: A report on research into the effects on young people of scenes of violence in films and television. London: British Film Institute (Education Department).

Grosswiler, P. (2006). The transformation of Carey on McLuhan: Admiration, rejection and redemption. Explorations in Media Ecology, 5(2), 137-148. doi: http://dx.doi.org/10.1386/eme.5.2.137_1

Halpern, R., \& Figueiras, A. C. M. (2004). Environmental influences on child mental health. Jornal de Pediatria, 80(2), 104-110. doi: http://dx.doi.org/10.1590/S0021-75572004000300013 
Hasebrink, U., Görzig, A., Haddon, L., Kalmus, V., \& Livingstone, S. (2011). Patterns of risk and safety online. In-depth analyses from the EU Kids Online survey of 9to 16-year-olds and their parents in 25 countries. LSE, London: EU Kids Online. Retrieved from http://eprints.lse.ac.uk/39356/.

Hasebrink, U., Livingstone, S., Haddon, L., \& Ólafsson, K. (2009). Comparing children's online opportunities and risks across Europe: Cross-national comparisons for EU Kids Online. LSE, London: EU Kids Online. Retrieved from http://eprints.lse.ac.uk/21656/.

Heins, M. (2008). Not in front of the children: "Indecency," censorship, and the innocence of youth (2nd Rev. ed.). New Brunswick, NJ: Rutgers University Press.

Helsper, E. J., Kalmus, V., Hasebrink, U., Ságvári, B., \& Haan, J. D. (2013). Country classification: Opportunities, risks, harm and parental mediation. LSE, London: EU Kids Online. Retrieved from http://eprints.lse.ac.uk/52023/.

Idate \& Technopolis (2014). Benchmarking of safer internet policies in member states and policy indicators: Final report. Retrieved from http://www.technopolis-group. $\mathrm{com} /$ ?report=benchmarking-safer-internet-policies-in-the-eu-member-states.

Internet Safety Technical Task Force (2008). Enhancing child safety and online technologies: Final report of the Internet Safety Technical Task Force to the multistate working group on social networking of state attorneys general of the United States. Boston, MA: Berkman Center for Internet \& Society at Harvard University.

Johnson, G. M., \& Puplampu, K. P. (2008). Internet use during childhood and the ecological techno-subsystem. Canadian Journal of Learning and Technology / La Revue Canadienne de L'apprentissage et de La Technologie, 34(1). Retrieved from http://www.cjlt.ca/index.php/cjlt/article/viewArticle/172.

Jordan, A. (2004). The role of media in children's development: An ecological perspective. Journal of Developmental \& Behavioral Pediatrics, 25(3), 196-206. doi: http://dx.doi.org/10.1097/00004703-200406000-00009

Jowett, G. S., Jarvie, I. C., \& Fuller, K. H. (1996). Children and the movies: Media influence and the Payne Fund controversy. Cambridge: Cambridge University Press.

Livingstone, S. (2013). „Knowledge enhancement”: The risks and opportunities of evidence-based policy. In B. O’Neill, E. Staksrud, \& S. Mclaughlin (Eds.), Towards a better Internet for children? Policy pillars, players and paradoxes. Goteborg: Nordicom. Retrieved from eprints.lse.ac.uk/59673/.

Livingstone, S., \& Haddon, L. (2009). EU Kids Online: Final report 2009. LSE, London: EU Kids Online. Retrieved from http://eprints.lse.ac.uk/24372/.

Livingstone, S., Haddon, L., \& Görzig, A. (2012). Children, risk and safety on the Internet: Research and policy challenges in comparative perspective. Bristol: Policy Press. doi: http://dx.doi.org/10.1332/policypress/9781847428837.001.0001

Lobe, B., Livingstone, S., Ólafsson, K., \& Vodeb, H. (2011). Cross-national comparison of risks and safety on the Internet: Initial analysis from the EU Kids Online survey of European children. LSE, London: EU Kids Online. Retrieved from http://eprints.lse.ac.uk/39608/.

Moody, K. (1999). The children of Telstar: Early experiments in school television production. New York, NY: Vantage Press. 
O'Neill, B. (2014). Policy influences and country clusters: A comparative analysis of Internet safety policy implementation. LSE, London: EU Kids Online. Retrieved from http://eprints.lse.ac.uk/57831/.

Palfrey, J., \& Gasser, U. (2010). Born digital: Understanding the first generation of digital natives. New York, NY: Basic Books.

Postman, N. (2000). The humanism of media ecology. Proceedings of the Media Ecology Association 1, 10-16. Retrieved from http://w.media-ecology.org/publications/MEA_proceedings/v1/postman01.pdf.

Prensky, M. (2001). Digital natives, digital immigrants. On the Horizon, 9(5). Retrieved from http://www.marcprensky.com/writing/Prensky\%20-\%20Digital\%20 Natives,\%20Digital\%20Immigrants\%20-\%20Part1.pdf. doi: http://dx.doi.org/10.1108/10748120110424816

Resnick, P., \& Miller, J. (1996). PICS: Internet access controls without censorship. Communications of the ACM, 39(10), 87-93.

doi: http://dx.doi.org/10.1145/236156.236175

Ross, S. M. (2009). Postman, media ecology, and education: From Teaching as a Subversive Activity through Amusing Ourselves to Death to Technopoly. Review of Communication, 9(2), 146-156.

doi: http://dx.doi.org/10.1080/15358590802326435

Schramm, W., Lyle, J., \& Parker, E. B. (1961). Television in the lives of our children. Palo Alto, CA: Stanford University Press.

Smahel, D., \& Wright, M. F. (2014). The meaning of online problematic situations for children. Results of qualitative cross-cultural investigation in nine European countries. LSE, London: EU Kids Online. Retrieved from http://eprints.lse.ac.uk/56972/.

Spitzer, M. (2012). Digital dementia: How we and our children are doing to our minds. Munich: Droemer.

Strate, L. (2004). A media ecology review. Communication Research Trends, 23(2), 3.

Surgeon General's Scientific Advisory Committee on Television and Social Behavior. (1972). Television and growing up: The impact of televised violence. Report to the Surgeon General, United States Public Health Service. Washington, D.C.: National Institute of Mental Health. 